\title{
Bilateral comparison of forearm skin temperature during handgrip force exercise
}

\author{
by R. Vardasca*, C. Magalhaes*, P. Abreu*, J Mendes*, M.T. Restivo* \\ *INEGI-LAETA, Faculdade de Engenharia, Universidade do Porto, Rua Dr. Roberto Frias 4200-465 Porto, \\ Portugal
}

\begin{abstract}
Handgrip force (HGF) test has been used to provide important occupational health information about subject's nutritional and physiological condition. Handgrip force (average and maximum) and exercise accumulated work can be measured using a dynamometer connected to a computer, other physiological energy spent in the HGF test can be obtained with infrared thermal (IRT) imaging at the anterior forearm region. A protocol has been developed combining both measurements, showing correlations between the measured values and the degrees of similarity between bilateral limbs was assessed, varying at maximum of $1.6^{\circ} \mathrm{C}$ in the considered thermal regions of interest of the forearm. The obtained results on 13 subjects at three different endurance HGF tests showed that the procedure is reproducible and can be applied in both limbs for physiological assessments in occupational, rehabilitation or geriatric contexts.
\end{abstract}

\section{Introduction}

Handgrip force (HGF) decline, aids to confirm muscle damage in the upper limbs [1], which may result from appearance of musculoskeletal disorders as a common sequel of body tissue aging [2] or affecting younger individuals as result of work-related tasks [3]. The assessment of HGF is possible through the use of dynamometers, a portable, easy to use and low-cost tool [4]. Depending on the type, dynamometers may be able to force, measuring torque and power [5, 6]. Apart from leased muscle tissue, blood circulation is also altered upon muscular mal-function [7].

A piece of research [8] demonstrated that aging accounts for $30 \%$ for males and $28 \%$ for females of the variance in HGF, and a faster decline in HGF occurs at the age of 30 for men and 50 years for women. Norman et al. [9] conducted a study where they concluded that muscle function reacts early to nutritional deprivation, and because of that HGF has also become an important indicator of nutritional status, becoming increasingly employed in nutritional intervention studies. They also identified that impaired HGF in patients was related with increased postoperative complications, increased length of hospitalization, higher re-hospitalization rate and decreased physical status. For elderly population the loss of grip strength implies loss of independence in their daily activities. A study published in 2011 [10] revealed that age and gender grip strength values are lower in younger adults than much of the international published population data, and there was not found any relationship of grip strength with elevated BMI.

In terms of bilateralism, a research published by Reikerås [11] concluded that when evaluating under pathological conditions the HGF, the bilateral hand should be also assessed and used as a useful parameter. Another research [12] found that the dominant hand is significantly stronger in right handed subjects but no such significant difference between sides could be documented for left handed people. Cornwell et al. [13] showed that for maximum handgrip contractions, the bilateral deficit may be related to preferential inhibition of the stronger hand, especially for individuals who are lefthand-strength-dominant in terms of unilateral force output, but the same was not found in the right-hand-strength-dominant.

Infrared thermal imaging (IRT) is an imaging method that maps the skin surface temperature distribution noninvasively and in a non-ionizing way. It can detect temperature changes which are related to blood flow and autonomic nervous system changes, reflecting physiological situations associated with musculoskeletal, vascular, autonomic nervous and locomotor systems [14, 15].

A previous study [16] has combined these two assessment methods and developed a methodology to quantify the physiological energy spent in the HGF exercise with IRT imaging, showing a statistical relationship between the two measurements, being therefore IRT used as a companion measurement to HGF. A recent research [17] verified the repeatability and consistency of the specified ROls, which were found to be robust and repeatable with minor influence of operator bias, also the same research group has built an automated approach to analyze the IRT images [18], which showed good correlation with the manual analysis. A recent study [19] showed differences in the two techniques combined in discriminating young and elder populations.

It is aim of this research to verify the bilateral differences among the limbs on the defined ROls at the forearm assessment on IRT images for reference to daily occupational medicine practice.

\section{Material and methods}

This research consists on the analysis of the thermal behaviour of the forearm skin, when subjected to HGF exercise with the two limbs. A total of 13 healthy participants ( 9 men and 4 women) with ages of $26 \pm 5$ years old, with a $26.0 \pm 4.5 \%$ of body mass index, were recruited to take part in the experiment.

The examinations started after 10 min' period of thermal equilibrium to the room conditions, followed by 3 different HGF exercises with a total duration of 50, 100 and 130 seconds, consisting of 5,10 and 15 grips of 5 seconds each. During this period, a baseline IRT image was firstly acquired, followed by the performance of the consecutive grips, ending with a 
resting phase were the participant remained holding the handgrip device over a forearm support (Fig. 1). Images were collected at a rate of 1 per second during the whole tests, which had taken place at different days but at same time.

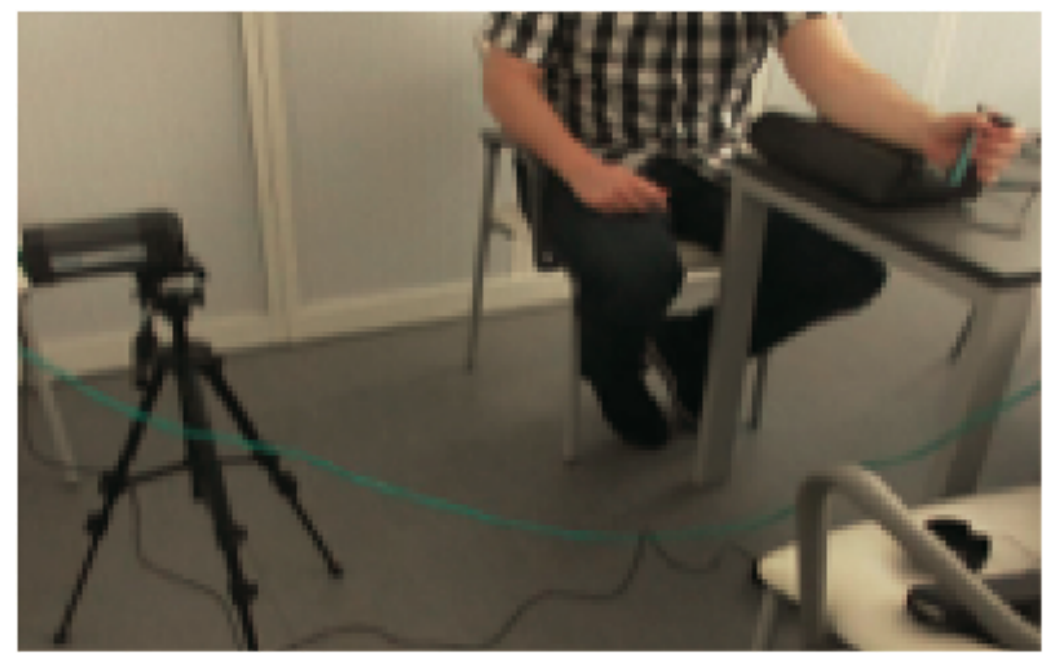

Fig. 1: The data capture setup.

The images were recorded by a thermal camera FLIR® (Wilsoville, OR, USA) A325sc (focal plane array sensor size of $320 \times 240$, a NETD of $<50 \mathrm{mK}$ at $30^{\circ} \mathrm{C}$ and a measurement uncertainty of $\pm 2 \%$ of overall reading), which was turned on 15 min before the first capture to ensure electronics thermal stability. The three Regions of Interest (ROI) considered for this test were: the ROI1 over the digital flexor muscle, the ROI2 over the wrist radial artery and the ROI3 over the wrist ulnar artery (Fig. 2). The images were analysed in the FLIR® (Wilsoville, OR, USA) ThermaCAM Researcher Pro 2.10 software package (Fig. 3).

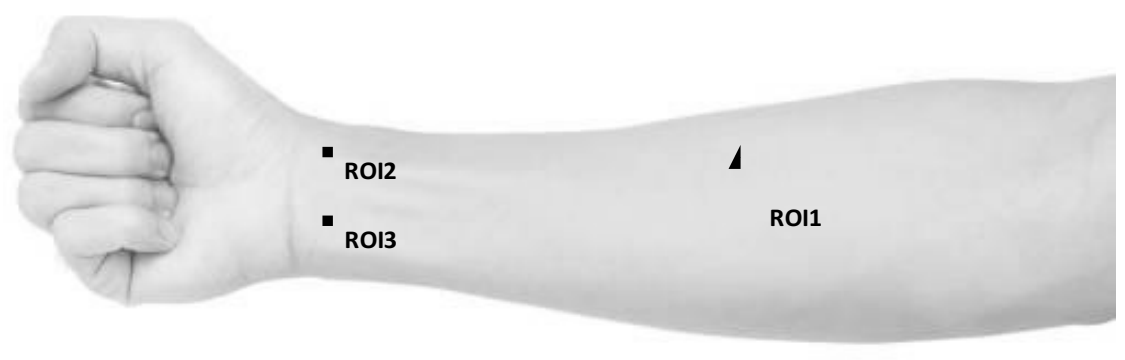

Fig. 2: The Regions of interest on the IRT image.

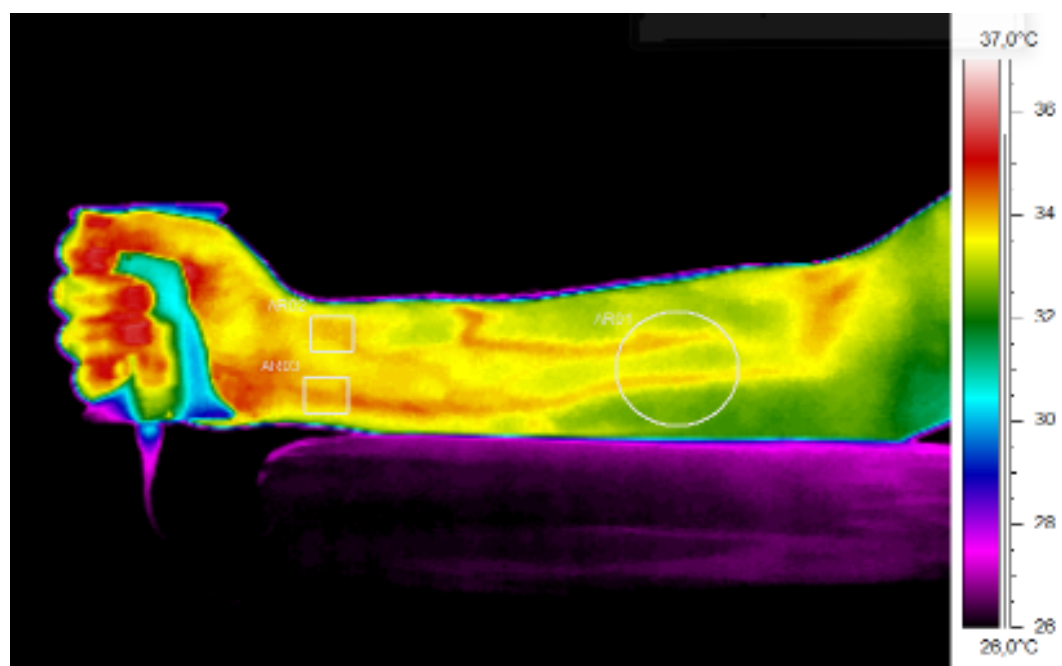

Fig. 3: Example of a forearm thermogram during HGF test on FLIR ThermaCAM Researcher Pro 2.10. 
This work has used a dynamometer prototype [16] developed at INEGI-LAETA, University of Porto, with patent application P300.3WO (September 2016). It offers a portable, fully instrumented dynamometer with wireless communication for reliable data recording and fast processing. It allows the analysis of grip force overtime and associated parameters that can be added to the traditional maximal grip strength for extended studies. Statistical assessments were performed with IBM SPSS v24, consisting of student t-test, Cohan's Kappa, Inter Class Correlation (ICC) coefficient and Bland-Altmann charts.

\section{Results}

The temperature variation for the HGF test of 5 consecutive grips is presented at Fig. 4, of 10 consecutive grips is presented at Fig. 5 and of 15 consecutive grips is presented at Fig. 6 for the three ROls and with the two forearms.

ROI1 - 5 consecutive grips of $5 \mathrm{~s}$ each

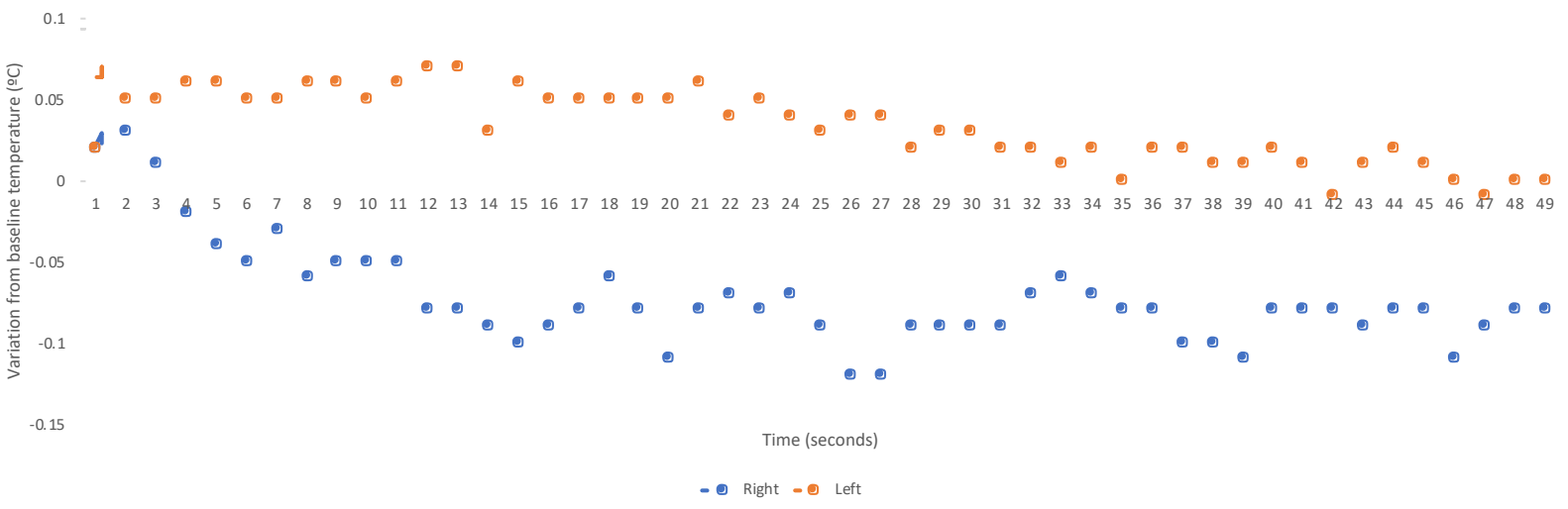

ROI2 - 5 consecutive grips of 5 s each

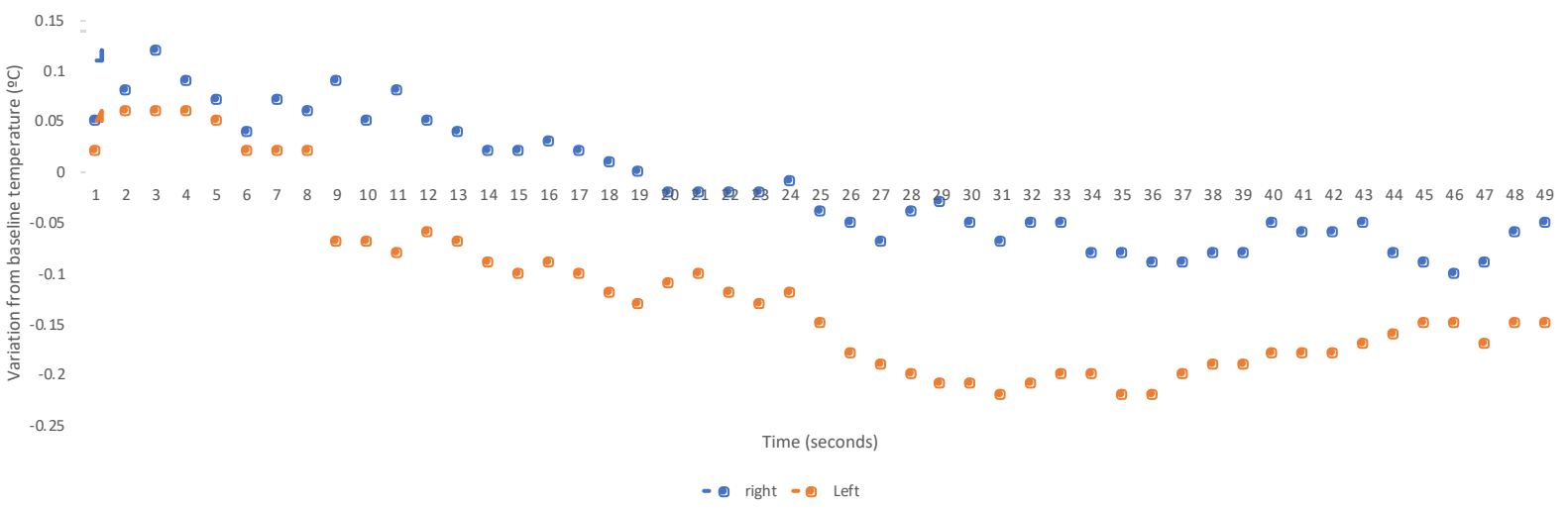

ROI3 - 5 consecutive grips of 5 s each

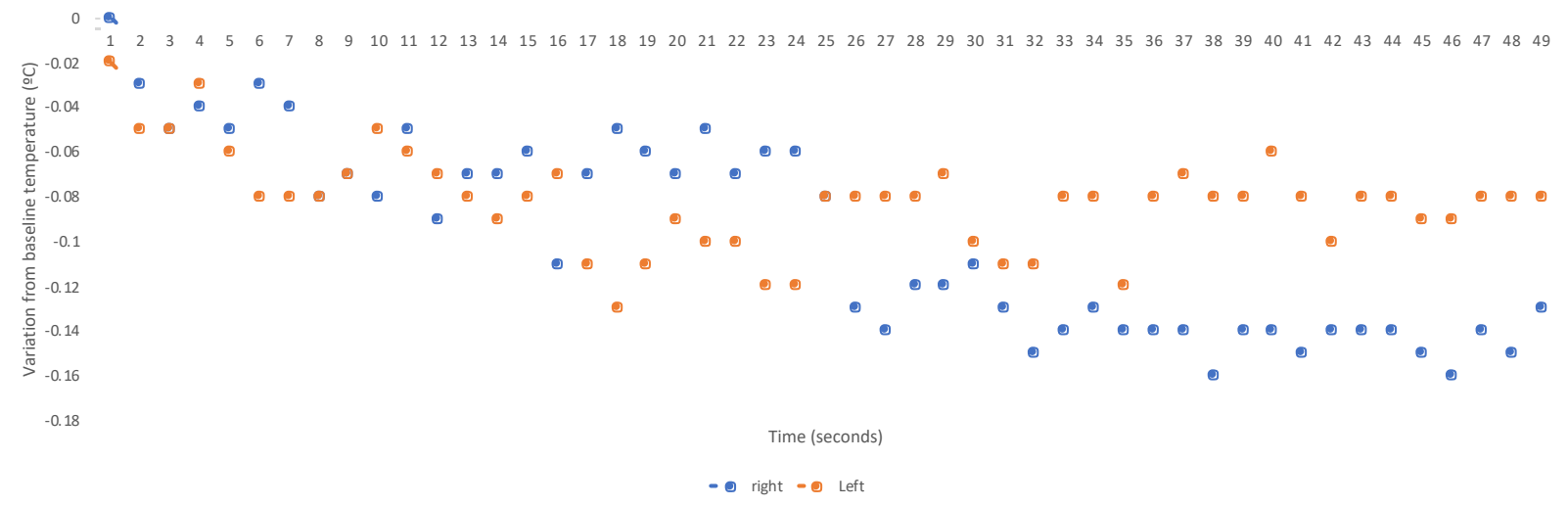

Fig. 4: The average temperature variation from baseline on the three ROIs and two forearms during the 5 consecutive grips of 5 seconds. 
ROI1 - 10 consecutive grips of $5 s$ each

0.15

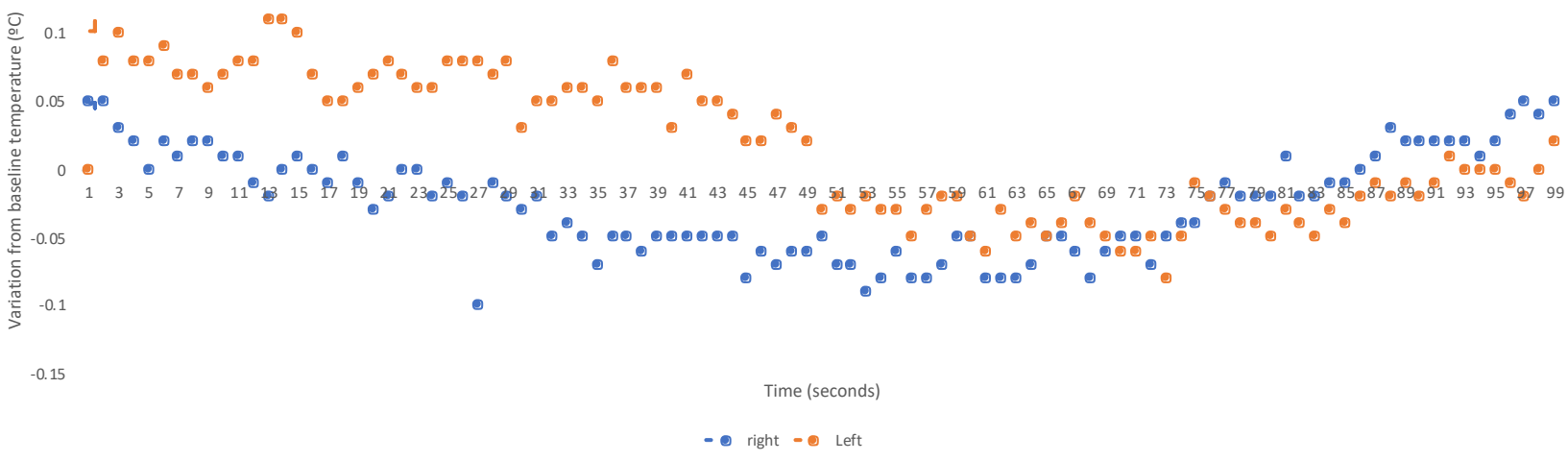

ROI2 - 10 consecutive grips of 5 s each

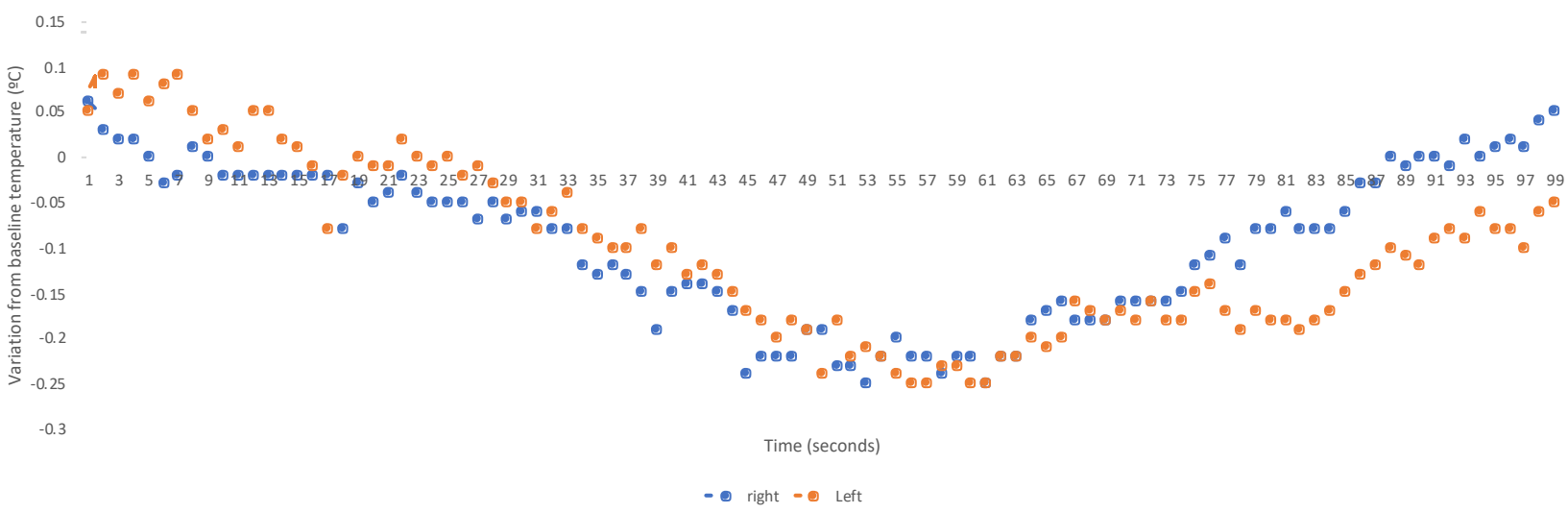

ROI3 - 10 consecutive grips of 5 s each

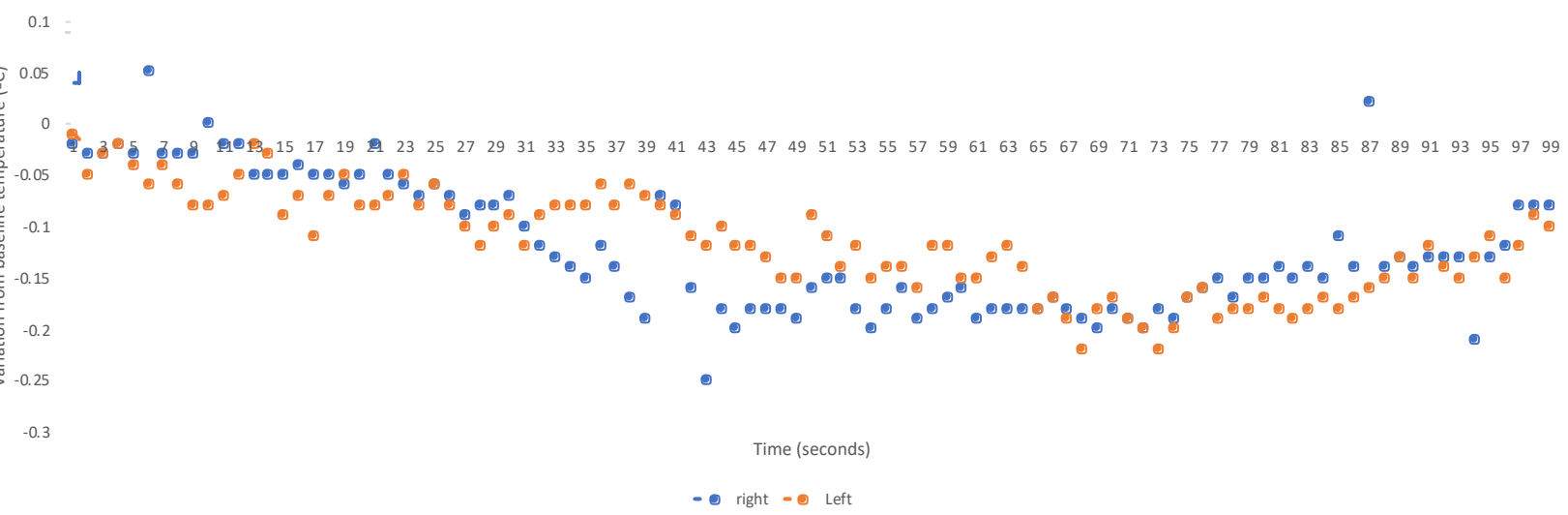

Fig. 5: The average temperature variation from baseline on the three ROls and two forearms during the 10 consecutive grips of 5 seconds. 

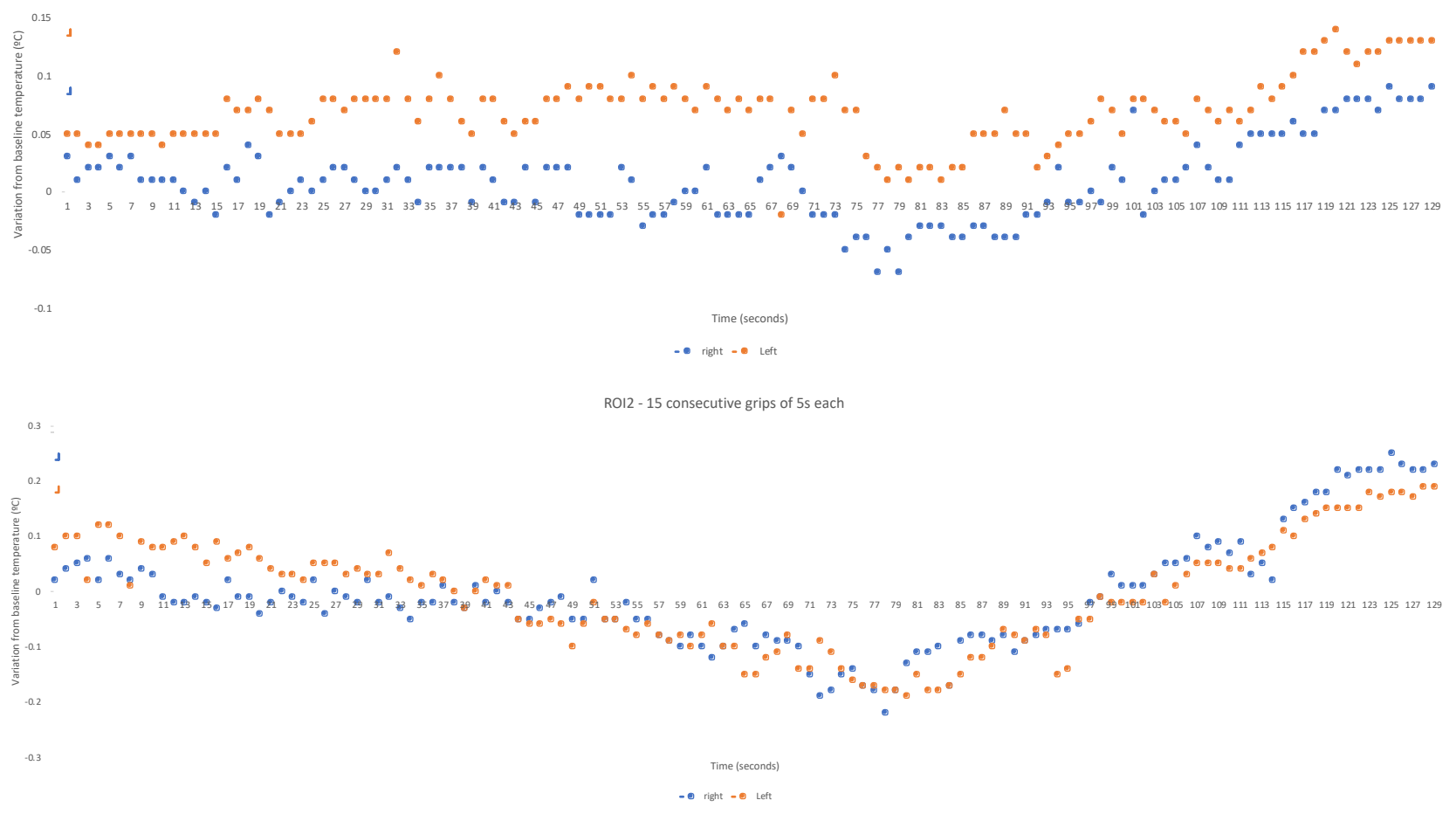

ROI3 - 15 consecutive grips of 5 s each

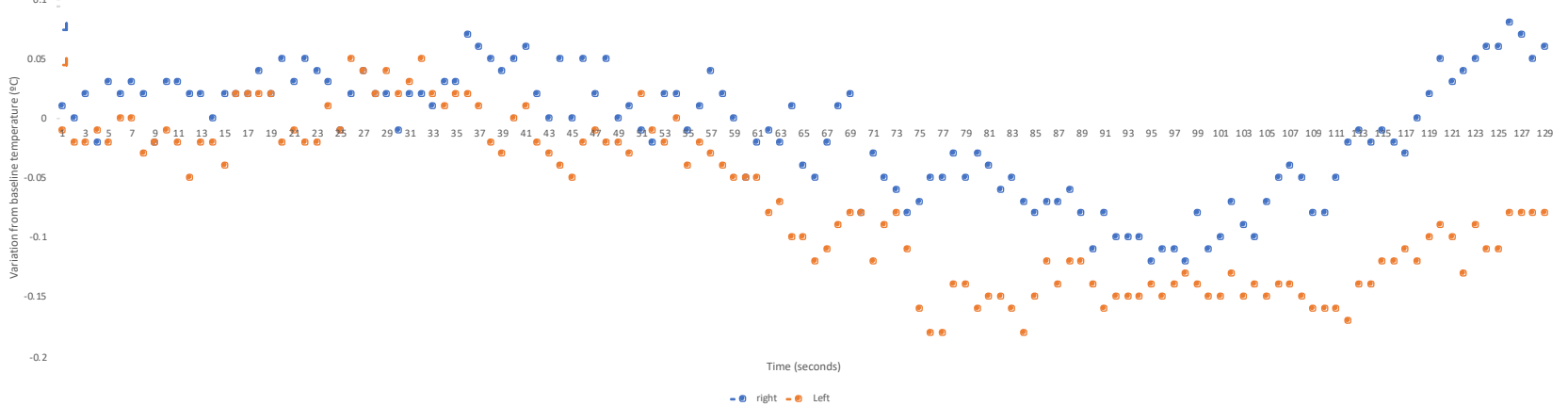

Fig. 6: The average temperature variation from baseline on the three ROIs and two forearms during the 15 consecutive grips of 5 seconds.

Comparing the ROls mean temperature during the 3 endurance tests of left and right limb and the grip force measured by the dynamometer, it was found only statistical evidence of side discrimination at the ROls in the IRT images $(p<0.05)$. The ICC statistics are shown at table 1.

Table 1. Results of ICC comparing left with right limbs.

\begin{tabular}{|l|c|c|c|}
\hline Measure & Alpha Cronbach's & ICC & ICC 95\% c.i. \\
\hline ROI1 & 0.825 & 0.702 & 0.685 to 0.718 \\
\hline ROI2 & 0.808 & 0.660 & 0.660 to 0.695 \\
\hline ROI3 & 0.853 & 0.743 & 0.729 to 0.758 \\
\hline Grip Force & 0.867 & 0.765 & 0.721 to 0.803 \\
\hline
\end{tabular}

The Cohen's Kappa, a robust measure of agreement values for bilateral ROI1, ROI2, ROI3 and grip force were $0.39,0.31,0.42$ and 0.00 correspondingly.

The Bland-Altmann charts showed a limit of agreement for ROI1 (Fig. 7), ROI2 (Fig. 8), ROI3 (Fig. 9) and grip force (Fig. 10) of $1.60^{\circ} \mathrm{C}, 1.35^{\circ} \mathrm{C}, 1.35^{\circ} \mathrm{C}$ and $8 \mathrm{~N}$ correspondingly. 


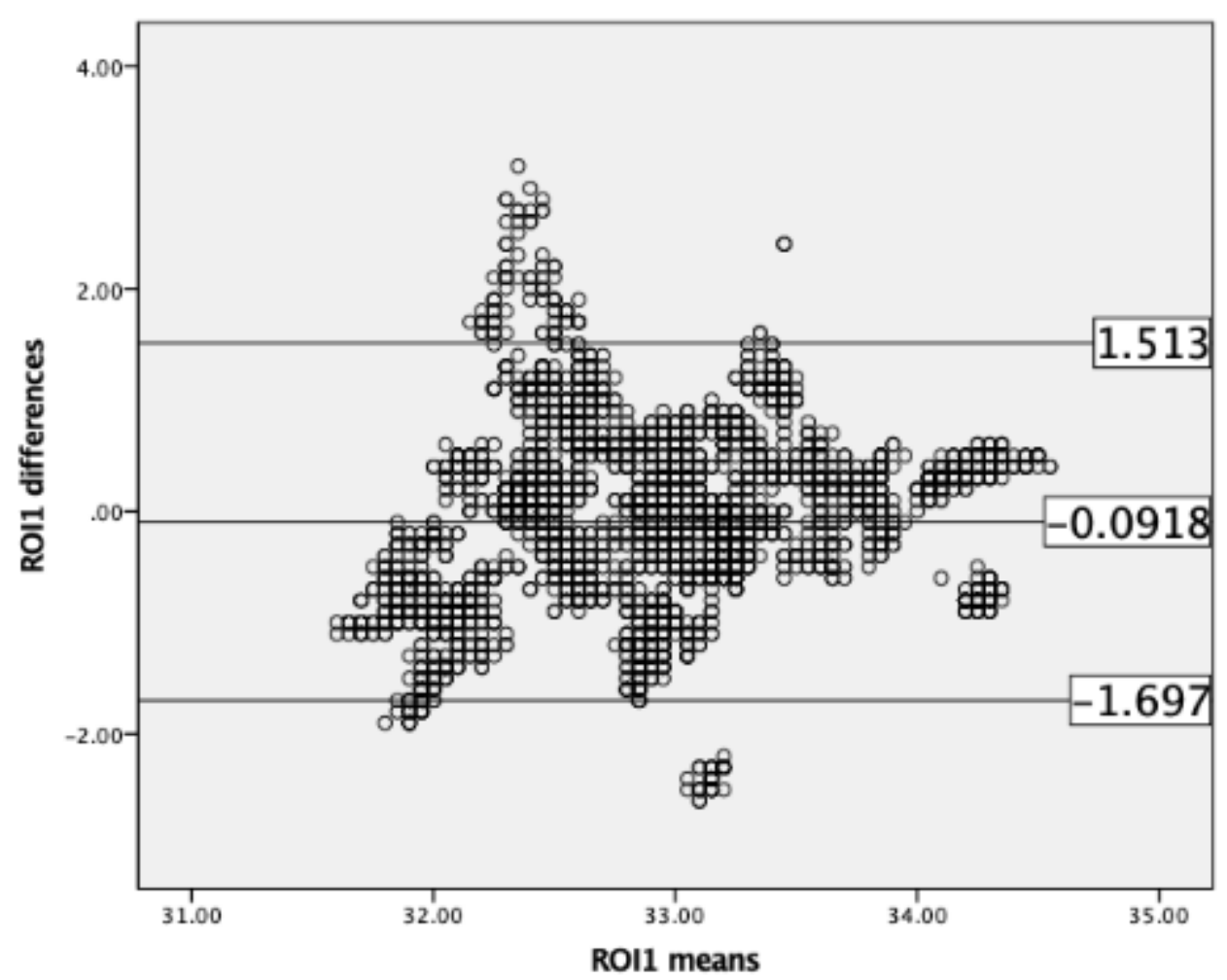

Fig. 7: The Bland-Altmann charts showing the limit of agreement for bilateral ROI1 average temperature variation from baseline between the three tests.

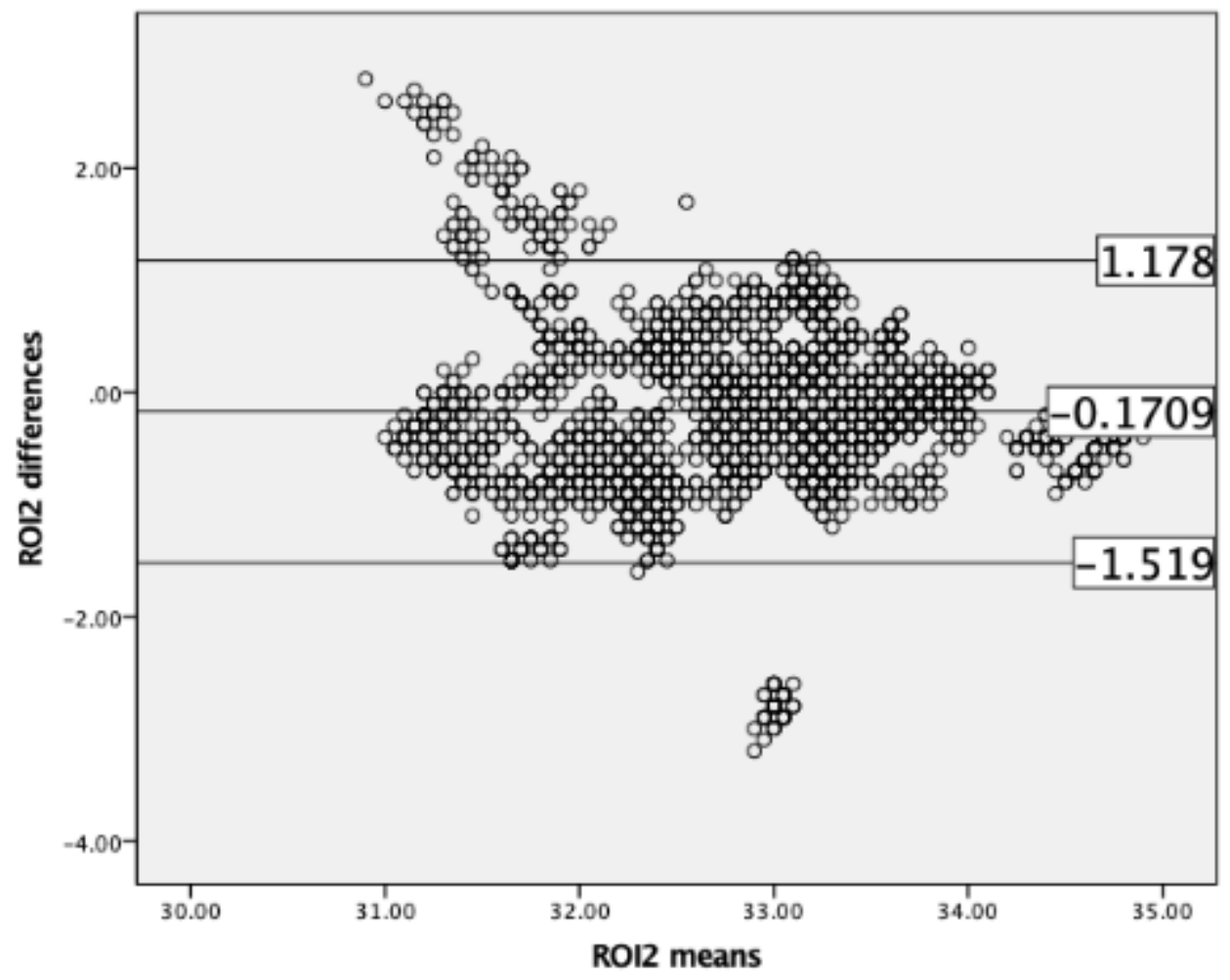

Fig. 8: The Bland-Altmann charts showing the limit of agreement for bilateral ROI1 average temperature variation from baseline between the three tests. 


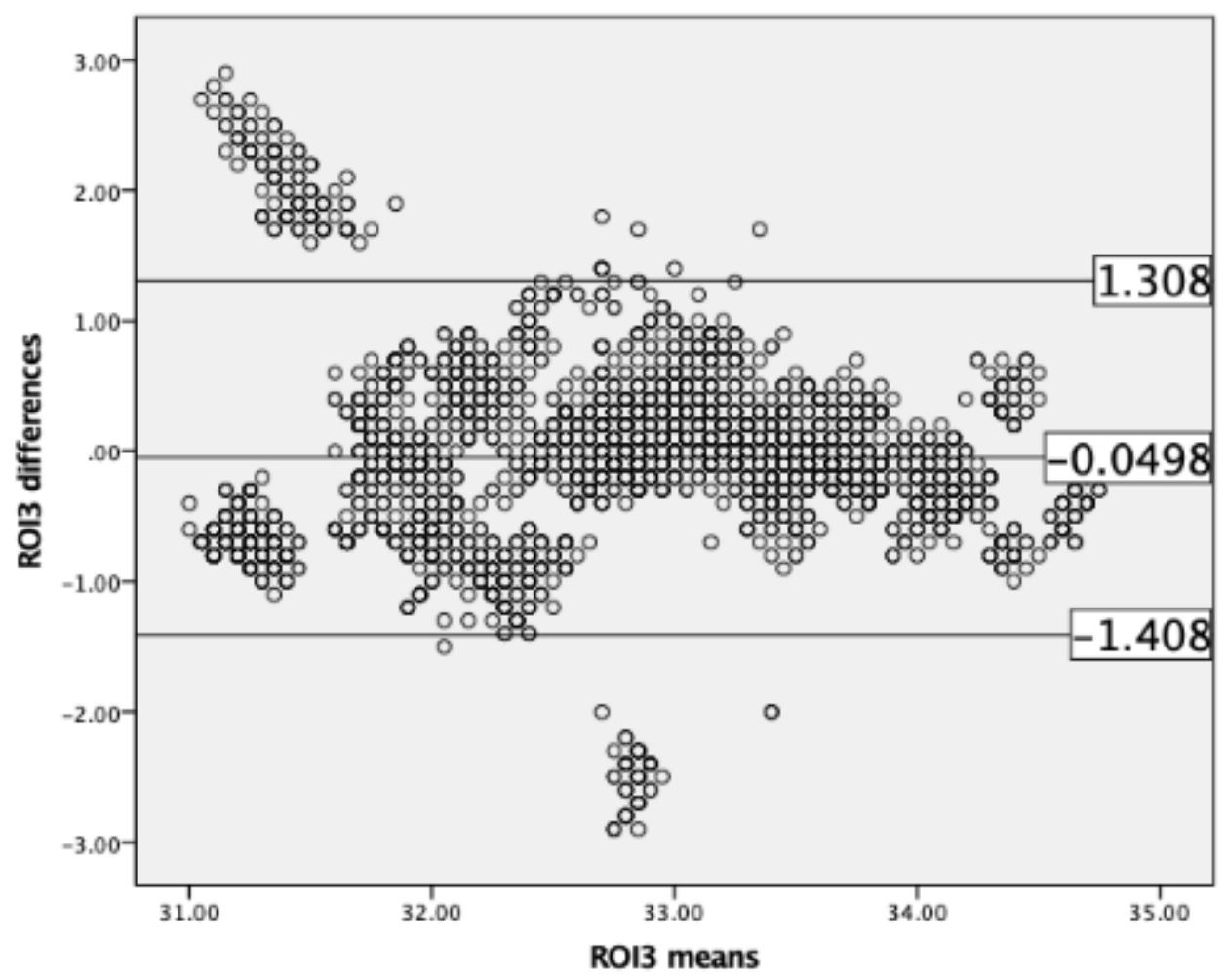

Fig. 9: The Bland-Altmann charts showing the limit of agreement for bilateral ROI2 average temperature variation from baseline between the three tests.

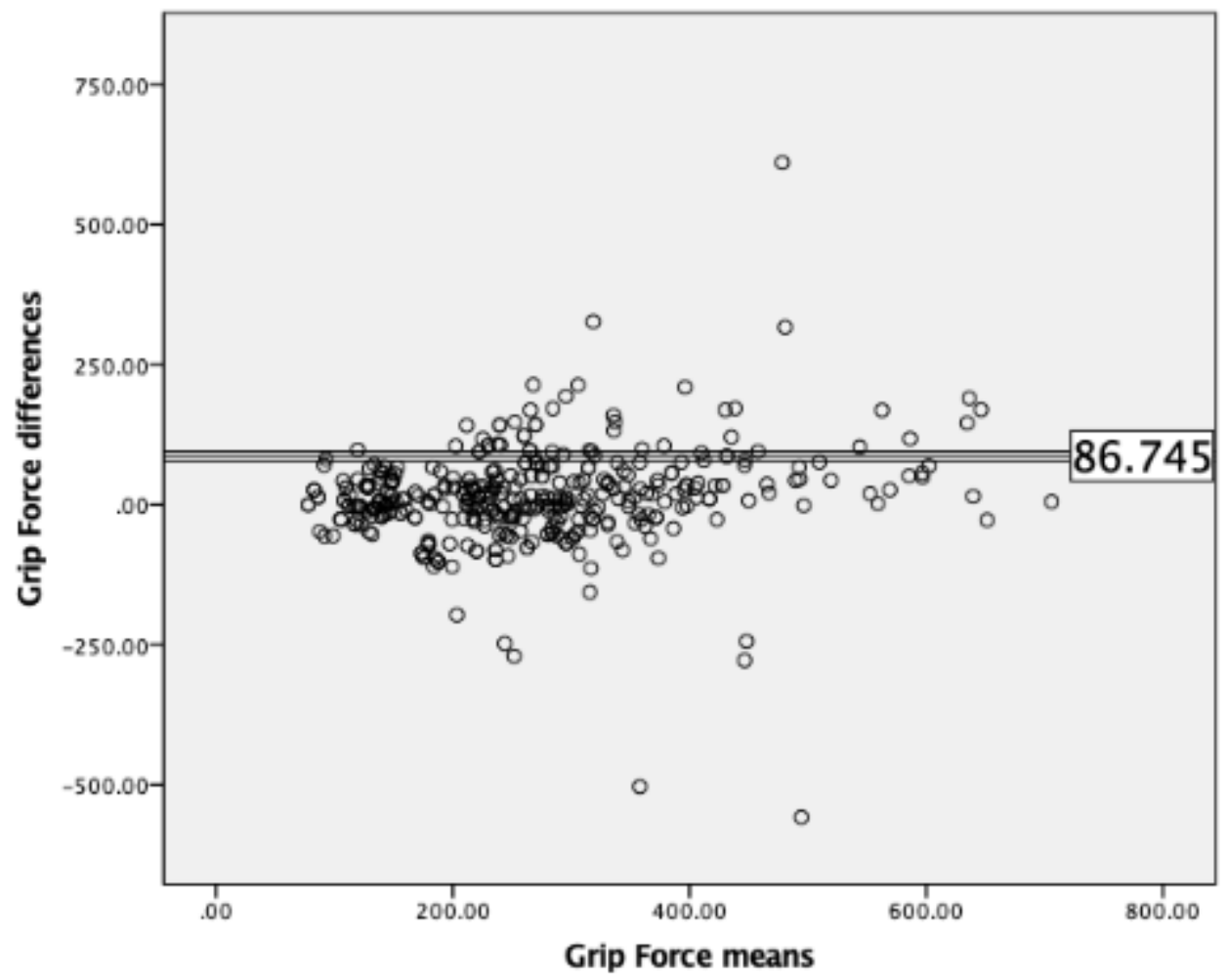

Fig. 10: The Bland-Altmann charts showing the limit of agreement for bilateral grip force average between the three tests. 


\section{Discussion}

From the results, it can be observed that despite of having only statistical evidence to reject the null hypothesis in the thermal variables to discriminate the bilateral side, there is a relative agreement between sides, which emphasizes that the developed methodology works equally for both sides but some attention has to be given in assessing bilateral differences, which must respect the limits of agreement. This enforces the combination of both methods in the physiological assessment of populations in upper limb muscular related condition risk.

Age, sex and BMI were not considered in this study, given its being a small sample to make such assessment and only right-hand-strength-dominant subjects were considered in this study.

The Cohen's kappa is reasonable with exception of the grip force parameter in bilateral agreement of ROls during HGF test. The ICC demonstrate a good agreement between the bilateral measurements and the alpha Cronbach's good data consistency. The Bland-Altmann analysis demonstrated the degree of agreement and accepted variance between bilateral measurements, which can be stated to be reasonable and not evident for single assessments.

Differences in the limits of agreement have to be taken into consideration in physical and physiological assessments as suggested by [12]. It is important to mention that this procedure is only valid when following the international guidelines for IRT use in medicine [15].

\section{Conclusion}

During HGF exercise monitored with IRT there was no statistical evidence $(p<0.05)$ of bilateral differences among the limbs on the defined ROls at the forearm assessment with infrared images for reference to daily occupational medicine practice. However, the degrees of similarity shown at the Bland-Altmann analysis have to be taken into consideration when using the ROIs temperature indicators. In this research only right-hand-strength-dominant participants took part, being the world population of right dominant hand estimated to represent a quota of $90 \%$.

\section{ACKNOWLEGMENTS}

Authors gratefully acknowledge the funding of Project NORTE-01-0145-FEDER-000022 - SciTech - Science and Technology for Competitive and Sustainable Industries, cofinanced by Programa Operacional Regional do Norte (NORTE2020), through Fundo Europeu de Desenvolvimento Regional (FEDER). This work was also funded by Project LAETA - UID/EMS/50022/2013.

\section{REFERENCES}

[1] Alperovitch-Najenson D, Carmeli E, Coleman R, Ring H. Handgrip strength as a diagnostic tool in work-related upper extremity musculoskeletal disorders in women. Sci. World J. 2004;4:111-117. http://dx.doi.org/10.1100/tsw.2004.12

[2] Badley EM, Crotty M. An international comparison of the estimated effect of the aging of the population on the major cause of disablement, musculoskeletal disorders. J. Rheumatol. 1995;22(10):1934-1940.

[3] Aptel M, Aublet-Cuvelier A, Cnockaert JC. Work-related musculoskeletal disorders of the upper limb. Joint Bone Spine 2002;69(6):546-555.

[4] Alberto R, Draicchio F, Varrecchia T, Silvetti A, lavicoli S. Wearable monitoring devices for biomechanical risk assessment at work: current status and future challenges - a systematic review. Int. J. Environ. Res. Public Health 2018;15(9):E2001. http://dx.doi.org/10.3390/ijerph15092001

[5] Gdula M, Burek J, Zylka L, Plodzien M. Five-axis milling of sculptured surfaces of the turbine blade. Aircraft Eng. Aerospace Technol. 2018;90(1):146-157. https://doi.org/10.1108/AEAT-11-2015-0242

[6] Mathissen M, Grochowicz J, Schmidt C, Vogt R, zum Hagen FHF, Grabiec T, Heinz S, Grigoratos T. A novel real-world braking cycle for studying brake wear particle emissions. Wear 2018;414:219-226. https://doi.org/10.1016/j.wear.2018.07.020

[7] Manson JJ, Isenberg D, Chambers S, Shipley ME, Merrill JT. Rapid Review of Rheumatology and Musculoskeletal Disorders, 1st edn. CRC Press, Boca Raton. 2014

[8] Vianna LC, Oliveira RB, \& Araújo, C. G. S. (2007). Age-related decline in handgrip strength differs according to gender. The Journal of Strength \& Conditioning Research 2007;21(4):1310-1314 https://doi.org/10.1519/R23156.1

[9] Norman K, Stobäus N, Gonzalez MC, Schulzke JD, Pirlich M. Hand grip strength: outcome predictor and marker of nutritional status. Clinical nutrition 2011;30(2):135-142 https://doi.org/10.1016/j.clnu.2010.09.010

[10] Massy-Westropp NM, Gill TK, Taylor AW, Bohannon RW, Hill CL. Hand grip strength: age and gender stratified normative data in a population-based study. BMC research notes 2011;4(1):127 https://doi.org/10.1186/17560500-4-127

[11] Reikerås O. Bilateral differences of normal hand strength. Archives of orthopaedic and traumatic surgery 1983;101(3):223-224 https://doi.org/10.1007/BF00436775

[12] Incel NA, Ceceli E, Durukan PB, Erdem HR, Yorgancioglu ZR. Grip strength: effect of hand dominance. Singapore medical journal 2002;43(5):234-237 
[13] Cornwell A, Khodiguian N, Yoo EJ. Relevance of hand dominance to the bilateral deficit phenomenon. European journal of applied physiology 2012;112(12):4163-4172 https://doi.org/10.1007/s00421-012-2403-z

[14] Ring EFJ, Ammer K. Infrared thermal imaging in medicine. Physiol. Meas. 2012;33(3):R33-R46. https://doi.org/10.1088/0967-3334/33/3/R33

[15] Lahiri BB, Bagavathiappan S, Jayakumar T, Philip J. Medical applications of infrared thermography: a review. Infrared Phys. Technol. 2012;55(4): 221-235. https://doi.org/10.1016/j.infrared.2012.03.007

[16] Vardasca R, Abreu P, Mendes J, Restivo MT. Handgrip Evaluation: endurance and handedness dominance. In International Conference on Remote Engineering and Virtual Instrumentation 2018:507-516. Springer, Cham https://doi.org/10.1007/978-3-319-95678-7_57

[17] Magalhaes C, Silva P, Vardasca R, Abreu $\bar{P}$, Mendes J, Restivo MT. (2019). Reliability of Forearm Skin Thermal Assessment During Handgrip Exercise. In Occupational and Environmental Safety and Health 2019:447-455. Springer, Cham https://doi.org/10.1007/978-3-030-14730-3_48

[18] Silva P, Vardasca R, Mendes J, Restivo MT. Towards an Automated Analysis of Forearm Thermal Images During Handgrip Exercise. In International Conference on Remote Engineering and Virtual Instrumentation 2018:498-506. Springer, Cham https://doi.org/10.1007/978-3-319-95678-7_56

[19] Magalhaes C, Silva P, Vardasca R, Abreu P, Mendes J, Restivo MT. Strength and Skin Temperature Assessment: Comparing Active and Geriatric Populations. International Journal of Engineering and Applied Sciences 2019;6(5):37-42. https://doi.org/10.31873/IJEAS.6.4.07 